\title{
Analysis of Associated Economic Loss of Meteorological Disasters among the Belt and Road Typical Countries —_ Taking the China's Typhoon Rammasun in 2014 as an Example
}

\author{
Changyuan Wang ${ }^{1}$, Xianhua $\mathrm{Wu}^{2,3}$, Lei $\mathrm{Zhou}^{4}$ \\ ${ }^{1}$ School of Management science and engineering, Nanjing University of Information Science \& \\ Technology, Nanjing 210044, China; \\ ${ }^{2}$ School of Economics and Management, Shanghai Maritime University, Shanghai 201306, \\ China; \\ ${ }^{3}$ Collaborative Innovation Center on Forecast and Evaluation of Meteorological Disasters, \\ Nanjing University of Information Science \& Technology, Nanjing 210044, China; \\ ${ }^{4}$ School of Applied Meteorology, Nanjing University of Information Science and Technology, \\ Nanjing 210044, China \\ “一带一路” 典型国家灾害的关联经济损失分析一 \\ 一以 2014 年中国 “威尔逊” 台风灾害为例 \\ 王长源 ${ }^{1}$, 吴先华 ${ }^{2,3}$, 周蕾 ${ }^{4}$ \\ 1 南京信息工程大学 管理工程学院, 江苏 南京 210044 中国; \\ 2 上海海事大学 经济管理学院, 上海 201306 中国; \\ 3 南京信息工程大学 气候与气象灾害协同创新中心, 江苏 南京 210044 中国; \\ 4 南京信息工程大学 应用气象学院, 江苏南京 210044 中国
}

\begin{abstract}
Under the background of economic globalization and regional economic integration, the associated economic losses caused by disasters to relevant regions and industries have increasingly become the focus and difficulty of people's attention. Based on the multiregional input-output model (MRIO model), this paper uses Typhoon Rammasun in 2014 as an example to calculate the associated economic losses to the "Belt and Road" typical countries. The results show that: (1) In 2014, the direct loss of the China's Typhoon
\end{abstract}

Rammasun in 2014 was 32.5 billion yuan, and the total loss of the entire economic system was as high as 121.7 billion yuan; (2) The typhoon disaster brought about the "Belt and Road" typical countries loss 550 million yuan. Among them, Russia, Indonesia and other countries suffered more serious losses; (3) The highly sensitive industries of the typhoon Rammasun mainly including manufacturing, supply of agriculture, forestry, animal husbandry and fishery, electricity, gas, steam, and air conditioning, Construction industry. This paper is a useful supplement to the 
cross-regional multi-sector disaster-related loss study. The results can provide a reference for the joint management of disaster prevention and reduction and disaster risk management among countries in the "Belt and Road".

Keywords: MRIO model; " Belt One Road"; Typhoon Rammasun; associated loss

\section{摘要}

在经济全球化和区域经济一体化的大 背景下, 灾害对相关区域和产业带来的关 联经济损失日益成为人们关注的重点和难 点。本文基于多区域投入产出模型 ( Multiregional Input-output Model, 简 称 MRIO 模型), 以 2014 年中国 “威马 逊” 台风灾害为例, 计算灾害对 “一带一 路” 典型国家带来的关联经济损失。结果 显示: (1)2014 年我国 “威马逊” 台风灾害 直接损失为 325 亿元, 整个经济系统的综 合损失高达 1217 亿元; (2) “威马逊” 台 风灾害对 “一带一路” 典型国家带来的关 联损失为 5.5 亿元。其中俄罗斯、印度尼 西亚等国家损失较为严重; (3) “威马逊” 台风灾害的高敏感行业主要包括: 制造业、 农林牧渔业、电力、燃气、蒸汽和空调的 供应、建筑业等。本文是跨区域多部门灾 害关联损失研究的有益补充, 结果可为“一 带一路” 国家间防灾减灾及灾害风险的联 动管理提供参考。

关键词: MRIO 模型; “一带一路”; “威 尔逊”台风; 关联损失

\section{1. 引言}

2013 年, 习近平总书记提出“一带一 路”的重大战略构想, 使亚欧非之间的政经 贸联系更加密切。目前“一带一路”沿线国 家虽然 GDP 水平普遍不高, 但是经济增长 速度较快, 具有巨大的发展潜力, 是世界 未来重要的增长极。同时, “一带一路”沿 线国家和地区环境复杂多样, 人口密集、 生态脆弱, 自然灾害频发, 不仅对本国居
民的生产生活造成严重影响, 还会对其他 国家带来关联影响。合理评估灾害带来的 关联损失, 不仅可以全面反映灾情, 还可 以为“一带一路”沿线国家合作开展防灾减 灾工作提供实证参考, 因而具有较好的理 论意义及实用价值。

所谓关联经济损失, 主要指由于灾害 直接破坏而引起的企业生产量下降的经济 损失, 企业厂房、设备遭受直接破坏后停 工停产带来的损失, 以及企业因上游企业 短缺原材料或者下游企业需求下降等产业 关联原因造成的损失等 (黄崇 福, 1999,2015 $5^{[1-2]}$; 李宁, $2017^{[3]}$ )。目前评估 关联经济损失的方法主要有两类。一是采 用可计算一般均衡模型 (Computable General Equilibrium Model, 简称 CGE 模 型) (Waters et al, $2010^{[4]}$; Koks et al, $2015^{[5]}$ ), 二是采用投入产出模型 (Input-Output Model, 简称 IO 模型) (Rose et al, $1997^{[6]}$; Okuyama et al, 2004) $)^{[7]}$ )。其 中, CGE 模型充分考虑各行为主体的供需 关系、商品要素的替代关系等经济行为, 通过捕捉部门和产业之间的链接, 进而评 估灾害造成的综合损失 (如曹玮, 2012 $2^{[8]}$; 解伟等, $2012^{[9]}$ ) 等。CGE 模型的计算结 果较为精确, 但对数据的要求高, 且参数 繁多, 计算过程复杂。IO 模型以投入产出 表为基础, 利用相应的线性代数模型, 反 映国民经济系统各个部门相互依存、相互 制约的关系 (张鹏等, $2012^{[10]}$; 吴先华 等 ,2012,2014,2016 $6^{[11-13] ; ~ H a l l e g a t t e, ~}$ $\left.2008^{[14]}\right)$, 需要的数据量小, 形式较为简 单, 原理清晰, 计算结果也较为可靠。由 于数据限制, 构建“一带一路”沿线主要国 家的 CGE 模型较为困难, 且很难设定各个 国家各部门的参数。因此, 这里采用世界 投入产出表 (World Input-Output Database, 简称 WIOD), 构建多区域投入产出模型 (Multiregional Input- output Model, 简称 MRIO 模型), 中国 2014 年发生的“威马 逊”台风灾害为例, 评估该次灾害给“一带 一路”沿线主要国家带来的关联损失。

本文的创新点主要包括以下三个方面: 
一是研究多国家 (区域)的灾害间接损失。 目前研究一个国家或区域内的关联损失较 多, 对跨国家间的关联损失研究较少。二 是运用 MRIO 模型评估灾害的间接损失。 目前 MRIO 模型多应用在区域间产业关联 强度研究 (韩斌, 2007 $7^{[15]}$; 郭富, 2016 $6^{[16]}$ )、 对外贸易隐含碳（间云凤，2013 ${ }^{[17]}$; 庞军, $2015^{[18]}$ ) 等研究中, 在多国家 (区域) 的 灾害间接损失研究中, 目前几乎没有人开 展研究。三是利用 MRIO 模型, 从总产出 关联损失和增加值关联损失两个角度分析 灾害对受灾部门造成的关联影响, 研究较 为完整。

\section{2. 模型与方法}

区域间投入产出表是区域间投入产出 模型的实证基础。典型的区域间投入产出 表是一张纵横交错的矩阵式平衡表格, 它 从生产的投入来源和产品的分配去向两个 方面描述各地区、各部门之间的经济联系 和分配关系, 可以全面系统地反映出不同 地区、不同部门的生产、分配、交换和消 费的完整的社会再生产过程。(陈锡康、杨 翠红等, 2011) ${ }^{[19]}$ 。具体形式如下表 1 所 示, 表中有 $\mathrm{m}$ 个不同的区域, 每个区域有 $\mathrm{n}$ 个不同的部门, 不同区域的部门分类方 法和口径一致。

表 1 区域间投入产出表

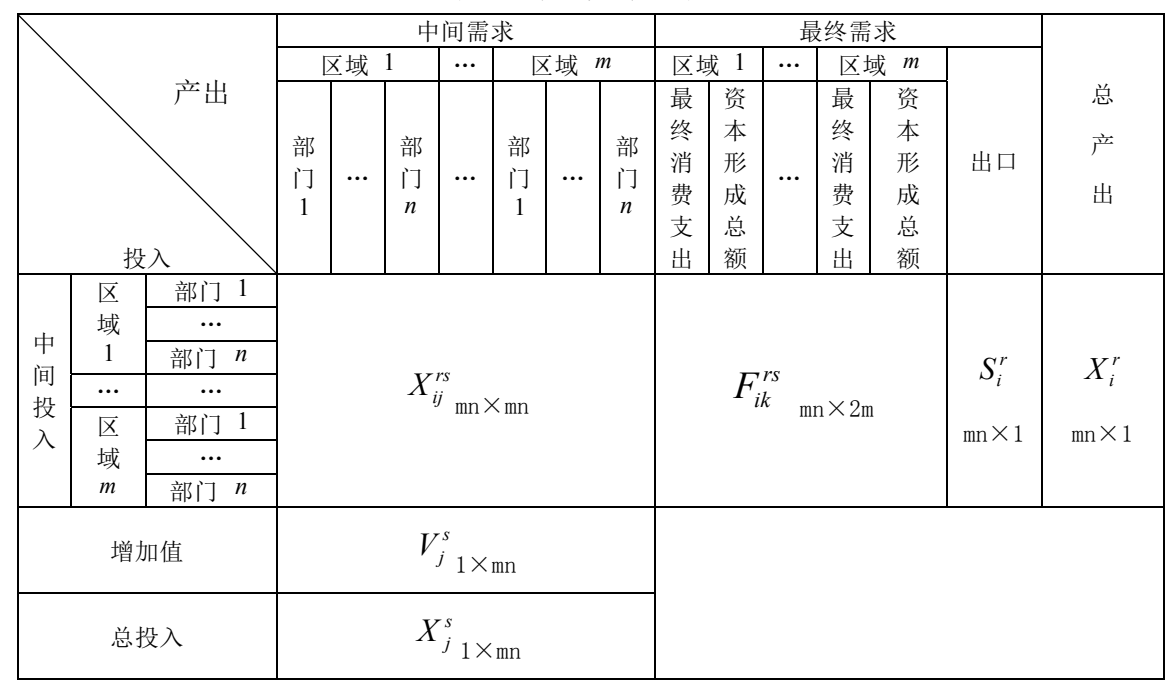

表 1 中, $X_{i j}^{r s} 、 F_{i j}^{r s}$ 都为 $(\mathrm{mn}) \times(\mathrm{mn})$

的方阵, $S_{i}^{r} 、 X_{i}^{r}$ 都为 $(\mathrm{mn}) \times 1$ 的列向量,

行方向的平衡关系是: 根据表 1 中行向的 平衡关系有以下式子:

$$
\sum_{s=1}^{m} \sum_{j=1}^{n} x_{i j}^{r s}+\sum_{s=1}^{m} \sum_{k=1}^{2} f_{i k}^{r s}+s_{i}^{r}=x_{i}^{r}, \forall r, i
$$

将最终需求矩阵 $F_{i k}^{r s}$ 和出口矩阵 $S_{i}^{r}$ 进行列项合并, 形成一个 $(\mathrm{mn}) \times 1$ 的列向
量 $C_{i}^{r}$, 即: $c_{i}^{r}=\sum_{s=1}^{m} \sum_{k=1}^{2} f_{i k}^{r s}+s_{i}^{r}$, 则行方

向的平衡关系可以表示如下:

$$
\sum_{s=1}^{m} \sum_{j=1}^{n} x_{i j}^{r s}+c_{i}^{r}=x_{i}^{r}, \forall r, i
$$

上式用矩阵的形式可以表示为:

$$
X_{i j}^{r s}+C_{i}^{r}=X_{i}^{r}
$$

规定 $a_{i j}^{r s}=X_{i j}^{r s} / X_{j}^{s}, a_{i j}^{r s}$ 为 $\mathrm{A}$ 中的元 素, 表示第 $\mathrm{s}$ 个区域第 $\mathrm{j}$ 各部门对第 $\mathrm{r}$ 个 
区域第 $\mathrm{i}$ 各部门产品的中间消耗, 也叫做 中间消耗系数。

整理后可以得:

$$
(I-A)^{-1} C_{i}^{r}=X_{i}^{r}
$$

变量形式为:

$$
(I-A)^{-1} \Delta C_{i}^{r}=\Delta X_{i}^{r}
$$

由于区域之间部门的关联性, 最终需 求 $C_{i}^{r}$ 的变化, 会引起总产出 $X_{i}^{r}$ 的变化。 根据路琮、魏一鸣、范英 (2002) ${ }^{[20]}$ 的研 究, 可将直接经济损失看作最终产品的损 失, 间接经济损失看作部门总产出的损失, 以上都是从多区域投入产出表的行角度出 发, 投入产出表中行平衡和列平衡同时存 在, 且各部门的总供给与总需求保持均衡, 从多区域投入产出表的列向角度出发, 列 方向的平衡关系矩阵形式表示如下:

$$
X_{\mathrm{ij}}^{r s}+V_{j}^{s}=X_{j}^{\mathrm{s}}
$$

上式中间投入 $X_{\mathrm{ij}}^{r s}$ 与增加值 $V_{j}^{r}$ 的和 等于总投入 $X_{j}^{s}$

$$
\text { 直接分配系数 } \tilde{a_{i j}^{r s}}=X_{i j}^{r s} / X_{i}^{r}, \forall r, i \text {, }
$$

其中 $X_{i}^{r}$ 为第 $\mathrm{r}$ 地区第 $\mathrm{i}$ 部门的总产出。

将直接分配系数代入列方向平衡关系 (6) 得:

$$
a_{i j}^{r s} X_{i}^{r}+V_{j}^{s}=X_{j}^{s}
$$

又因为各地区各部门总投入等于总产 出, 上式用矩阵的形式可以表示为:

$$
A^{T} X_{j}^{s}+V_{j}^{s}=X_{j}^{s}
$$

整理后得:

$$
V_{j}^{s}=\left(1-A^{T}\right) X_{j}^{s}
$$

变量形式为:

$$
\Delta V_{j}^{s}=\left(1-A^{T}\right) \Delta X_{j}^{s}
$$

在已知总产出损失和中间消耗系数矩 阵, 可估算各地区各部门增加值损失。

以上可以利用 MRIO 模型从总产出关 联损失和增加值关联损失 2 个角度分析灾 害对受灾部门冲击后给受灾部门的总体影 响, 以此评估受灾部门造成的区域整体经 济影响。

\section{3. 案例及数据说明}

\section{1 案例说明}

台风“威马逊” 首次于 2014 年 7 月 18 日 15 时 30 分左右在海南文昌市翁田镇 沿海登陆, 18 日 19 时 30 分左右又在广东 徐闻县龙塘镇沿海登陆, 19 日 7 时 10 分 左右在广西防城港市光坡镇沿海再次登陆, 登陆时中心风力达到 17 级, 中心最低气压 910 百帕。灾害的突然发生使得交通运输、 能源供应、电力传输、农业及人民群众生 活等方面带来极为严重的影响。不仅给我 国关联产业带来巨大损失, 还对 “一带一 路” 沿线国家和地区造成严重的风险。基 于此, 本文以我国 2014 年 “威马逊” 台风 灾害为例进行实证。

\section{2 数据来源}

(1) 灾情数据。结合民政部网站 22 日发布消息及广东、广西、海南、云南等 省(区)民政厅报告的数据, “威马逊” 造成 洪涝、风霖、泥石流等灾害, 导致 46 人死 亡、 25 人失踪。 144 个县(市、区) 996.6 万 人受灾, 62.8 万人紧急转移安置, 25.2 万 人需紧急生活救助; 农作物受灾面积 1898.7 千公顷, 其中绝收 250.3 千公顷; 直接经济损失达 336.5 亿元。综合人民网、 中国新闻网、国际在线、受灾省份政府网 等媒体报导, 损失主要集中在以下六个方 面: 农林牧渔业、市政设施的损失、工业 园区的损失、住宅房屋倒塌和交通港航损 失。本文以这六个典型行业作为分析对象, 研究关联国家和部门的关联损失。

（2）投入产出表。目前 “一带一路” 主要包含 65 个国家, 但目前大家经常使用 的世界投入产出表 (World Input-Output Database, 简称 WIOD) 数据表中有 40 个 
国家的数据。根据 WIOD 中的数据的完整 性和可获得性, 选取了 16 个典型国家: 保 加利亚、中国、塞浦路斯、捷克、爱沙尼 亚、匈牙利、印度尼西亚、印度、立陶宛、 拉脱维亚、波兰、罗马尼亚、俄罗斯、斯 洛伐克、斯洛文尼亚、土耳其。

(3) 产业部门。将 2014 年 WIOD 中 的 56 个部门合并为 20 个部门 ${ }^{[21]}: 1$-农林 牧渔业; 2-采矿业; 3-制造业; 4-电力、 燃气、蒸汽和空调的供应; 5-供水; 污水 处理、废物管理和补救活动; 6-建筑业; 7-批发和零售业; 汽车、摩托车的修理; 8-交通运输和仓储; 9-住宿和餐饮; 10-信 息和通信; 11-金融业; 12-房地产业; 13专业、科学和技术活动; 14-行政和辅佐活 动; 15-公共管理与国防以及强制性社会保 障; 16-教育; 17-人体健康和社会工作; 18-其他服务业；19-家庭作为雇主的活动; 家庭自用、未加区分的物品生产和服务活 动; 20-国际组织和机构的活动。

\section{4. 实证结果}

(1)总产出关联损失。采用公式 (5), 从行向角度估算关联损失, 计算结果详见 表 2 和图 1。首先从关联国家的间接损失 计算结果来看, 中国的总产出关联损失最 大, 达到 363.1 亿元。除中国外, 15 个 “一 带一路” 典型国家损失的总产出关联损失 达到 2.2 亿元。其中, 俄罗斯最为严重, 达到 1.1 亿元。印度尼西亚和印度的总产 出关联损失都超过 0.1 亿元。其次, 从各 部门总产出关联损失来看, 20 个部门的总 产出关联损失达到 365.3 亿元。其中制造 业的影响最大, 为 190.5 亿元。其次是电 力、燃气、蒸汽和空调的供应、采矿业、 农林牧渔业等。

(2)增加值关联损失。采用公式 (10), 从列向角度估算不同国家不同部门的关联 损失。中国的增加值关联损失最大, 达到 848.5 亿元, 远远大于总产出关联损失。 除中国外, 15 个典型 “一带一路” 国家的 损失为 3.2 亿元。其中, 俄罗斯最为严重, 达到 1.5 亿元。印度尼西亚和印度的增加 值关联损失都超过 0.5 亿元, 土耳其和波
兰超过 0.1 亿元。从部门增加值的关联损 失来看, 20 个部门的损失达到 851.7 亿元。 制造业的损失最为严重, 达到 325.3 亿元, 其次为农林牧渔业、电力、燃气、蒸汽和 空调的供应、建筑业、交通运输和仓储业 等。

(3) 综合损失。该值是总产出关联损 失与增加值关联损失之和。从表 2 可见, 除了中国损失最为严重外, 15 个其他 “一 带一路” 国家的关联损失达到 5.5 亿元。 其中俄罗斯和印度尼西亚关联损失均超过 1 亿元。这说明灾害不仅对本地区产业造 成冲击, 还对多国家 (地区) 关联产业带 来了严重损失。

\begin{tabular}{|c|c|c|c|}
\hline 国家 & $\begin{array}{l}\text { 总产出关联 } \\
\text { 损失（亿元） }\end{array}$ & $\begin{array}{l}\text { 增加 值 关 } \\
\text { 联损失 ( 亿 } \\
\text { 元) }\end{array}$ & $\begin{array}{l}\text { 综 合损 失 } \\
\text { （亿元） }\end{array}$ \\
\hline 保加利亚 & 0.02222 & 0.032287 & 0.054507 \\
\hline 中国 & 363.06151 & 848.4887 & 1211.55021 \\
\hline 塞浦路斯 & 0.00037 & 0.000517 & 0.000887 \\
\hline 捷克 & 0.05518 & 0.080589 & 0.135769 \\
\hline 爱沙尼亚 & 0.00339 & 0.004825 & 0.008215 \\
\hline 匈牙利 & 0.02854 & 0.042206 & 0.070746 \\
\hline 印度尼西亚 & 0.50908 & 0.752892 & 1.261972 \\
\hline 印度 & 0.33576 & 0.510374 & 0.846134 \\
\hline 立陶宛 & 0.00328 & 0.004838 & 0.008118 \\
\hline 拉脱维亚 & 0.00275 & 0.004023 & 0.006773 \\
\hline 波兰 & 0.06848 & 0.10117 & 0.16965 \\
\hline 罗马尼亚 & 0.01823 & 0.027124 & 0.045354 \\
\hline 俄罗斯 & 1.09125 & 1.521052 & 2.612302 \\
\hline 斯洛伐克 & 0.01131 & 0.016616 & 0.027926 \\
\hline 斯洛文尼亚 & 0.00400 & 0.005813 & 0.009813 \\
\hline 土耳其 & 0.09445 & 0.135732 & 0.230182 \\
\hline
\end{tabular}

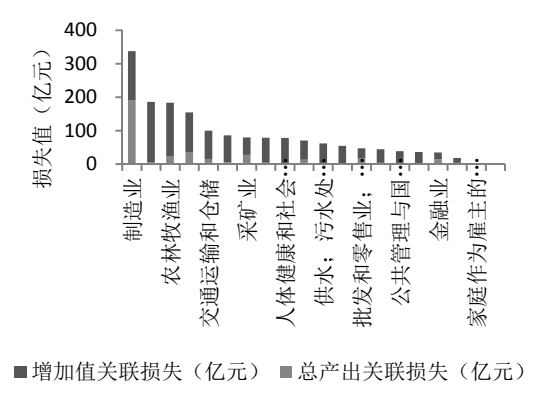

图 1 各行业部门总产出关联损失和增加值关联 损失 


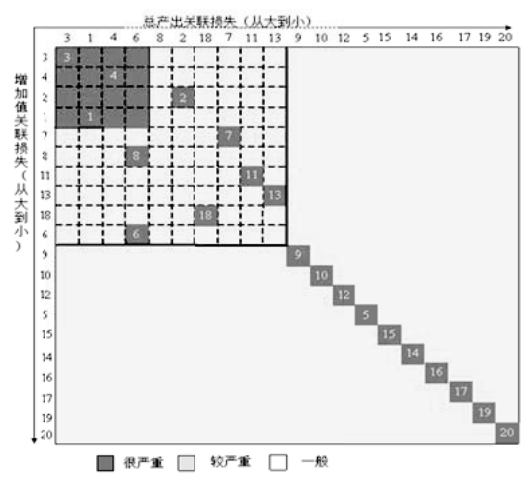

图 2 各行业部门总产出与增加值损失分类矩阵 （其中数字 3、1、4……等代表产业部门序号,

详见 3.2 数据来源中产业部门)

为了更加直观看出 20 个部门的受灾 程度, 本文采用系统聚类的方法, 根据平 方 Euclidean 距离度量标准, 把 20 个受灾 部门的灾损设定为三个等级: 很严重、较 严重和一般 (见上图 2)。由图 1、图 2 可 知, “威马逊” 台风灾害受影响最大的部门 包括: 1-农林牧渔业、3-制造业、4-电力、 燃气、蒸汽和空调的供应、6-建筑业、8-

\section{Acknowledgements}

This study was supported by National Natural Science Foundation of China(No. 91546117, No.71373131); National Social Science Major Bidding Project of China (No. 16DA047); National Soft Science Project(No. 2011GXQ4B025)

交通运输和仓储、其他服务业等。再从总 产品损失与增加值损失考虑, 将矩阵分成 3 个区域: 很严重、较严重、一般。从受 影响部门来看, 3-制造业、4-电力、燃气、 蒸汽和空调的供应、1-农林牧渔业是高敏 感部门; 另外较为严重的有 7 个部门, 一 般严重的有 10 个部门。救灾、重建工作应 该着重考虑高敏感行业, 并根据部门受灾 情况有针对性地开展灾后重建工作。

\section{5. 结论}

随着 “一带一路” 的持续推进, 国家
间各个产业间的关联将不断增加, 如何衡 量多国家 (地区) 的灾害关联损失研究是 社会各界关心的重点。本文构建了灾害关 联损失评估模型, 以 2014 年 “威马逊” 台 风灾害为例, 对 “一带一路” 16 个典型国 家开展实证分析, 得到的主要结论如下:

(1) 本文所采用的 MRIO 模型能够 科学全面地度量灾害带来的关联损失, 可 为部门合理安排救灾、制定应急措施以及 多国家 (地区) 的灾后重建提供理论依据 和数据支撑。

（2）本文以 2014 年世界投入产出表 为基础, 从总产品损失与增加值损失两个 角度计算灾害的关联损失。结果显示, 2014 年 “威马逊” 台风灾害对我国带来的综合 损失约为 1212 亿元, 其他 15 个 “一带一 路” 国家的综合损失为 5.5 亿元, 其中俄 罗斯和印度尼西亚损失最为严重。“威马逊” 台风灾害的高敏感性行业为制造业、农林 牧渔业、电力、燃气、蒸汽和空调的供应、 建筑业等, 今后要重点对这些产业开展监 测和扶持工作。

\section{致谢}

本研究得到了国家自然科学基金 (91546117, 71373131); 国家社科重大招标 项目 (16DA047); 国家软科学计划项目 (2011GXQ4B025)的资助

\section{参考文献:}

[1] 黄崇福, 自然灾害风险分析的基本原 理, 自然灾害学报，(2): 21-30，1999.

[2] 黄崇福, 自然灾害动态风险分析基本 原理的探讨, 灾害学, (2): 1-7, 2015.

[3] 李宁, 张正涛, 陈曦, 等, 论自然灾 害经济损失评估研究的重要性, 地理 科学进展，36（2)：256-263，2017.

[4] E. C. Waters, K. S. Chang. Impacts of Recent Shocks to Alaska Fisheries: A Computable General Equilibrium (CGE) Model Analysis, Marine Resource Economics, 25(2):155-183, 2010. 
[5] E. E. Koks, L. Carrera, O Jonkeren, et al. Regional disaster impact analysis: comparing input-output and computablegeneral equilibrium models, Natural Hazards \& Earth System Sciences Discussions, 16(8):1911-1924, 2016.

[6] A. Rose, J. Benavides, S. E. Chang, et al. The regional economic impact of an earthquake: direct and indirect effects of electricity lifeline disruptions, Journal of Regional Science,37, 437-458, 1997.

[7] Y. Okuyama. Modeling spatial economic impacts of an earthquake: Input-output approaches, Disaster Prevention and Management, 13(4), 297-306, 2004.

[8] 曹玮, 肖皓, 基于 CGE 模型的极端冰 雪灾害经济损失评估, 自然灾害学报, 21 (5): 191-196, 2012.

[9] 解伟, 李宁, 胡爱军, 等, 基于 CGE 模型的环境灾害经济影响评估一以 湖南雪灾为例, 中国人口·资源与环境, 22 (11): 26-31，2012.

[10] 张鹏, 李宁, 刘雪琴, 等, 基于投入 产出模型的洪涝灾害间接经济损失定 量分析, 北京师范大学学报 (自然科 学版), 48 (4): 425-431, 2012.

[11] 吴先华, 徐中兵, 袁迎蕾, 等, 台风 灾害的关联经济损失评估一以江 苏省为例, 灾害学, 29 (2): 77-83, 2014.

[12] 吴先华, 聂国欣, 郭际, 陈云峰, 基 于技术系数矩阵的灾害影响评估及政 策启示, 科学学研究, 30 (11): 1676-1683, 2012.

[13] 吴先华, 朱薇薇, 王荣荤, 等, 基于 改进 ITIM 模型的政治争端事件对产 业经济系统的影响评估, 中国管理科 学, 2: 27-37, 2016.

[14] S. Hallegatte. An adaptive regional input-output model and its application to the assessment of the economic cost of Katrina, Risk Analysis An Official Publication of the Society for Risk Analysis, 28(3):779-799, 2008.

[15] 韩斌, 刘朝明, 李亮, MRIO 模型在 区域间产业关联强度研究中的应用, 生产力研究, 153 (16): 115-117, 2007.

[16] 郭富, 基于产业关联的东北区域发展 研究, 哈尔滨工业大学, 2016.

[17] 间云凤, 赵忠秀, 王苒, 基于 MRIO 模型的中国对外贸易隐含碳及排放责 任研究, 世界经济研究, (6): 54-58, 2013.

[18] 庞军, 石媛昌, 谢希, 等, 基于 MRIO 模型的中美欧日贸易隐含碳特点对比 分析, 气候变化研究进展, 2015, 11 (3): 212-219.

[19] 陈锡康, 杨翠红, 投入产出技术, 科 学出版社, 2011.

[20] 路琮, 魏一鸣, 范英, 等, 灾害对国 民经济影响的定量分析模型及其应用, 自然灾害学报，11(3):15-20，2002.

[21] 廖明球, 投入产出及其扩展分析, 北 京: 首都经济贸易大学出版社, 2009 . 